\title{
O PENSAMENTO POLÍTICO DE DANTE ALIGHIERI NO TRATADO DE MONARCHIA
}

Gabriel Ferreira de Almeida Paizani Orientação: Fátima Regina Fernandes

PALAVRAS-CHAVE: História do pensamento político; filosofia medieval; Baixa Idade Média.

A produção de Dante Alighieri possui dois lados: um do pensador político e outro do poeta. A opção nessa pesquisa foi pelo primeiro, dando um enfoque completo ao tratado De Monarchia (1312-3). Essas duas linhas estão relacionadas, mas procurei delimitar esse espaço para tentar não ultrapassar as fronteiras da história do pensamento político. Estudos sobre Dante Alighieri e sua produção, notadamente sobre seu lado teórico, são escassos no Brasil. Uma pesquisa destinada a suprir essa lacuna histórica, por meio do Monarchia, torna-se fundamental para uma discussão mais plural sobre as teorias políticas tardo-medievais, o que permitirá compreender como algumas idéias e instituições se constituíram ou eram questionadas naquele período.

Assim, essas produções filosóficas e políticas não devem ser colocadas em segundo plano, como normalmente sucede, originando a fixação da Commedia em um patamar elevado, em contraste a tratados como o Monarchia e Convivio, percebidos como obras menores. Afinal, estes são fundamentais para um entendimento completo da edificação intelectual dantesca. Um estudo que esclareça questões como as motivações e influências para a escrita dessas obras preenche, mesmo que parcialmente, esse espaço vazio existente.

A Europa Ocidental, e principalmente Florença, há mais de um século conhecia intensa atividade econômica e intelectual, acelerado crescimento demográfico/territorial e desenvolvimento de novas formas sociais e políticas. "A Itália, como acontecera por toda Idade Média, também no século XIII era uma espécie de síntese 
européia". ${ }^{1}$ Nela ocorriam de maneira muito acentuada os conflitos entre o Papado e um dos agentes do poder temporal - o Sacro Império Romano Germânico. Esse desenvolvimento populacional e o fortalecimento econômico das cidades italianas levaram essas sociedades a se rebelarem contra as antigas autoridades locais, bispos e senhores feudais. De forma que, desde fins do século XI e início do XII, muitas comunidades urbanas passaram a indicar seus próprios dirigentes, gerando as comunas/cidades-estado. ${ }^{2}$ Como em quase todas as comunas, a nobreza florentina era de origem feudal. Com grandes posses e interesses no campo, a participação desse estrato na vida urbana dava-se através da atividade militar que garantia grande prestígio e o exercício do poder. Mas, à medida que as atividades comerciais se desenvolviam, a nobreza tinha sua autoridade diminuída. Assim, em 1293, com a Ordenação da Justiça, nova legislação imposta pelo restante da população, os nobres viram decretado o fim de seus privilégios. Isso legitimava o fato de Florença ser governada pela camada de grandes comerciantes. ${ }^{3}$

Dante Alighieri nasceu em Florença no seio de uma família de origem nobre. Com grande atividade política no partido favorável ao imperador (guelfos brancos), chegou a ser, nos últimos anos do século XIII, membro do conselho e priore de Florença. Recebeu sua educação de ordens religiosas (dominicanos e franciscanos), uma formação genuinamente escolástica, representando um intelectual e um escritor que conheceu e utilizou as argumentações filosóficas, canonísticas, legistas e teológicas sabendo vinculá-las entre si de modo independente e efetivo. No entanto, pouco se sabe sobre a formação intelectual do pensador, mas que certamente ele cumpriu os dois estágios básicos da educação medieval, o trivium e o quadrivium, que compunham as chamadas sete artes liberais herdadas de Roma. No primeiro estudava-se gramática (língua latina e literatura), retórica

\footnotetext{
${ }^{1}$ FRANCO JR. Hilário. Dante Alighieri: o poeta do absoluto. São Paulo: Atêlie Editorial, 2002, p. 15.

${ }^{2}$ Ibid., p. 17.

${ }^{3}$ Ibid., pp. 21-2.
} 
(estilística e história) e dialética (iniciação filosófica). No segundo, aritmética, geométrica, astronomia (astrologia e física) e música (estudo das freqüências e intervalos, bem como das relações de consonância). ${ }^{4}$

Dante resistiu às intervenções de Bonifácio VIII nos negócios internos de Florença e por isso militou junto aos guelfos brancos. Foi enviado para Roma para persuadir este pontífice a não deixar que Carlos de Valois, enviado pelo papa sob as falsas vestes de pacificador em Florença, ajudasse os guelfos negros, favoráveis à política papal, a se protegerem dos donos do governo da cidade. E como isso não aconteceu, Dante voltou de Roma, não só de mãos vazias, como já no caminho foi informado de que os seus adversários políticos, os guelfos negros, tinham-no condenado, sob a acusação de corrupção, a pagar uma multa de cinco mil florins e a dois anos de prisão, além de interdição perpétua aos ofícios públicos. A acusação era falsa e a condenação, emitida em 27 de maio de 1302, atingia-o injustamente. Por isso, recusou-se a pagar a multa, e escolheu a via do exílio. A partir de então, passou por diversas cidades italianas, como Verona, Pádua, Treviso, Veneza e Ravena, sempre sob a proteção de nobres ligados ao imperador. Morreu em 1321, sendo enterrado em Ravena, onde atualmente encontram-se seus restos mortais.

Durante a Baixa Idade Média, o Sacro Império Romano Germânico passava por uma crise interna desde a morte de Frederico II em 1250, acarretando uma ausência de autoridades, não só imperiais, como eclesiásticas, tendo em vista, por exemplo, o exílio de Avinhão em 1307. Em conjunto a isso, os constantes conflitos entre a esfera temporal e espiritual de poder, principalmente entre seus respectivos representantes na Baixa Idade Média, Filipe IV e Bonifácio VIII, e a fracassada empreitada de Henrique VII pela Itália, em conjunto às colisões entre as facções políticas guelfas e gibelinas, forneceram a base empírica para o nascimento de pensadores originais em suas propostas para a resolução desse complexo contexto.

${ }^{4}$ Ibid., p. 52. 
O político e o religioso para esse homem medieval eram indissociáveis, ele tinha consciência de pertencer a uma sociedade única, a Respublica Christiana, fundamentada pela fé cristã, a qual não dependia do homem, mas provinha de Deus e nele encontrava seus princípios a serem obedecidos. Assim, a teoria de Gelásio I de admissão de dois guias para a Cristandade não era facilmente aceita ou, pelo menos, trazia graves conseqüências para a vida social, organizada em vista do bem comum. A tese gelasiana separava a auctoritas sacerdotal e a potestas régia, atribuindo superioridade a primeira em razão da dignidade, conduzindo para uma noção de comunidade quasi monstrum com duas cabeças. De forma que o espiritual seria superior ao material, motivado pelo neoplatonismo de redução da multiplicidade o Sumo Pontífice seria o chefe único da Ecclesia-Christianitas e o Imperador seria o braço armado e protetor da Igreja. ${ }^{5}$

Como nos afirmam os autores João Morais Barbosa e José Antônio de C. R. de Souza, na história das idéias políticas, pelo menos no que concerne à Idade Média, verifica-se com freqüência um fenômeno curioso, o das teorizações mais sólidas de uma instituição sócio-política surgirem quando a materialização dessas teorias se manifesta em declínio ou até na impossibilidade de se firmar. A idéia de Império novamente se fortaleceu quando ele passou a ser uma abstração sem fundamento prático na realidade. ${ }^{6}$ O florentino Dante Alighieri foi um dos que percebeu essas questões com maior agonia, seu desejo de unidade e de resgate da figura régia fez com que produzisse o tratado Monarchia.

Entre o ano de 1312 e 1313, Dante Alighieri decidiu abordar o problema da sociedade universal, influenciado por seu contexto complexo de dissensões e pela figura imperial de Henrique VII.

\footnotetext{
${ }^{5}$ BARBOSA, João Morais; SOUZA, José Antônio de C. R. de. O Reino de Deus e $o$ Reino dos Homens. As relações entre os poderes espiritual e temporal na Baixa Idade Média (da Reforma Gregoriana a João Quidort). Porto Alegre: EDIPUCRS, 1997, p. 116.

${ }^{6}$ Ibid., p. 149.
} 
Assim, "vítima da divisão, esperava ardentemente a unidade". ${ }^{7}$ Por mais que os ideais apresentados no tratado Monarchia não sejam novos, o sentido desenvolvido a partir de seus elementos é singular: distinguir o poder temporal e espiritual, assumindo também a complementaridade entre eles.

Apesar de intitulado Monarchia, não se trata da defesa de um regime político, mas antes a busca pela unidade na universalidade, ou seja, o ideal de uma sociedade do gênero humano verdadeiramente total. Assim, o principal postulado é a afirmação de que o poder temporal teria sua origem diretamente de Deus, fundamentando a defesa de um único sistema capaz de estabelecer e garantir regras para o novo modo de conceber as relações políticas e sociais. Esse aparato seria a Monarquia Universal, capaz de prover a felicidade para a comunidade humana.

A Monarquia temporal, que se chama Império, seria o único principado que se ergue sobre todos os seres que vivem no tempo, ou sobre tudo aquilo que é medido pelo tempo. Assim, três questões poderiam ser levantadas sobre a Monarquia: (1) se é ela indispensável para boa ordenação do mundo; (2) se o povo romano se atribuiu com legitimidade o exercício da Monarquia; e (3) se a autoridade da monarquia lhe vem imediatamente de Deus, ou lhe é, antes, concedida por intermédio dum ministro ou vigário de Deus.

O passado é o tempo da tradição, superior às novidades ameaçadoras que o presente traz, toda realidade presente é legitimada pela referência a um fundador. No tratado Monarchia há a tentativa de resgatar o passado glorioso italiano, o Império Romano é o seu majestoso referencial, tradição construída no presente para justificar sua proposta de uma nova realidade, sendo que sua caracterização se deve ao fato de que nenhuma prática pode ser aceita nela se não for percebida como a repetição de uma experiência antiga. Dessa forma, durante a Idade Média toda a energia para reformar a realidade social deve ser entendida como um retorno a um passado fundador e a recuperação de valores perdidos, a formação do Império Carolíngio,

${ }^{7}$ GILSON, E. Evolução da Cidade de Deus. São Paulo: Herder, 1965, p. 100. 
por exemplo, representa a ressurreição do Império Romano, antes que uma inovação. ${ }^{8}$

O papado e o império seriam instituições estabelecidas por Deus para a adequada orientação da humanidade; ambos derivavam e referiam-se a Deus - dessa forma, tornavam-se comparáveis apenas quando reduzidos a Ele. O Monarca Universal deveria representar o "homem em seu máximo", o optimus homo, no sistema da Monarchia, o imperador e o filósofo coincidiam, para que o imperador não carecesse de justificação ética e moral para sua tarefa natural de guiar a humanidade, mediante o emprego da razão filosófica. O monarca de Dante não era simplesmente um homem da espada e, com isso, o braço executivo do papado; seu monarca era necessariamente um poder filosófico-intelectual por seus próprios méritos. Era encargo principal do imperador, por meio da razão natural e da filosofia moral a que pertencia a ciência legal, guiar a mente humana para a beatitude secular, tal como o papa era encarregado pela Providência de guiar a alma cristã para a iluminação supranatural. ${ }^{9}$

Dante cria um tratado sem possibilidades de ser aplicado naquele momento, buscando um passado italiano de predestinação, num momento em que a fé e a lógica ainda não eram bem aceitos em conjunto. Sustenta uma distinção mais precisa entre o poder temporal e espiritual, não implicando necessariamente numa oposição ou separação entre eles, haja vista o duplo fim do homem, o qual deve ser guiado pelo Imperador e pelo Papa.

Para um intelectual da Idade Média tardia, fazer política significa escolher entre as duas grandes expressões do poder deste período: o papado e o Império. Contudo, essa opção resulta em exercícios obrigatórios, como a discussão teórica, essencialmente

\footnotetext{
${ }^{8}$ BASCHET, Jérôme. A civilização feudal. Do ano mil a colonização da América. Rio de Janeiro: Globo, 2006, pp. 319-320.

${ }^{9}$ KANTOROWICS. Ernst E. Os dois corpos do rei: um estudo sobre teologia política medieval. Trad. Cid Knipel Moreira. São Paulo: Companhia das Letras, 1998, p. 280.
} 
teológica e jurídica, sobre a independência do poder político em relação ao poder religioso. Dante Alighieri, como um dos principais defensores medievais do ideal monárquico, escreve o tratado político Monarchia, permitindo a essa pesquisa apresentar e discutir a questão tipicamente medieval da delimitação da soberania do poder temporal e do poder espiritual.

Filósofo e cristão, Dante reconhece dois ideais: o sucesso filosófico, a felicidade nesta terra, e a bem-aventurança segundo os teólogos, a visão bem-aventurada prometida aos eleitos na Jerusalém celeste. O modelo agostiniano das duas cidades sobrepõe-se assim à ideia do filósofo-rei. Como afirma Alain de Libera, os medievais em geral não dissertam sobre os méritos comparados da democracia e da oligarquia; eles se interessam apenas pela monarquia. A idéia-força é que a sociedade cristã é dual, que isso não ameaça sua unidade, mas antes a reforça. $\mathrm{O}$ homem é uno e duplo, a sociedade na qual ele vive deve sê-lo também. "Dante não quebra a sociedade cristã, ele descobre o seu pluralismo". ${ }^{10}$

${ }^{10}$ LIBERA, Alain de. A filosofia medieval. São Paulo: Loyola, 1998, p. 452. 